\title{
The role of health anxiety among patients with chronic pain in determining response to therapy
}

\author{
Heather D Hadjistavropoulos PhD, Gordon JG Asmundson PhD, \\ Diane L LaChapelle MA, Allisson Quine BA
}

HD Hadjistavropoulos, GJG Asmundson, DL LaChapelle, A Quine. The role of health anxiety among patients with chronic pain in determining response to therapy. Pain Res Manage 2002;7(3):127-133.

Considerable research suggests that health anxiety (HA) influences the response of patients with chronic pain to pain and treatment. The present investigation extends the current understanding of HA and explores whether it affects how patients respond to a common therapeutic intervention, namely instructions to reduce pain behaviour. Sixty-five patients with chronic pain completed measures of pain, anxiety and cognition following an active occupational therapy session in which they were specifically instructed either to inhibit or reduce pain behaviour, or to carry out the session as they normally would. Regression analyses revealed that those with higher levels of HA experienced greater anxiety, somatic sensations and catastrophic cognitions during therapy than those with lower levels of HA. The regression analyses also revealed a consistent trend for an interaction between HA and instructional set; when those with higher HA reduced their pain behaviour, they subsequently reported greater anxiety, and more somatic sensations and catastrophic thoughts than when they carried out the session as they normally would. In contrast, only those with lower HA had a tendency to benefit from reducing pain behaviour, reporting lower state anxiety and fewer somatic sensations during the session than those who did not reduce their pain behaviour. The results suggest that HA should be taken into consideration during treatment.

Key Words: Chronic pain; Health anxiety; Pain behaviour; Therapy

Anxiété relative à l'état de santé chez les patients souffrant de douleurs chroniques et réaction au traitement

RESUME : De nombreuses recherches donnent à penser que l'anxiété relative à l'état de santé a une incidence sur la réaction à la douleur et au traitement chez les patients souffrant de douleurs chroniques. La présente étude va au-delà de la compréhension actuelle de ce type d'anxiété et tente de vérifier s'il influe sur la réaction des patients à une intervention thérapeutique commune, soit des directives visant à atténuer le comportement révélateur de la douleur. Soixante-cinq patients atteints de douleurs chroniques ont été soumis à des mesures de la douleur, de l'anxiété et de la cognition à la suite d'une séance d'ergothérapie active au

voir page suivante

Clinical Research and Development Program, Regina Health District, Department of Psychology, University of Regina, Regina, Saskatchewan Correspondence and reprints: Dr Heather D Hadjistauropoulos, Associate Professor, Department of Psychology, University of Regina, Regina, Saskatchewan S4S 0A2. Telephone 306-585-5133, fax 306-585-4827,

e-mail hhadjista@uregina.ca 
cours de laquelle ils avaient reçu la consigne ou bien d'inhiber ou d'atténuer le comportement de la douleur ou bien de poursuivre normalement leurs activités. Les analyses de régression ont révélé que les patients très anxieux éprouvaient plus d'anxiété, de sensations somatiques et de pensées cognitives effrayantes durant la séance d'ergothérapie que les patients moins anxieux. Les analyses ont aussi révélé une tendance constante à l'interaction entre l'anxiété et les consignes, c'est-à-dire que les sujets plus anxieux qui atténuaient le comportement de la douleur ont fait état d'un degré plus élevé d'anxiété, de sensations somatiques et de pensées effrayantes que ceux qui poursuivaient normalement leurs activités. En revanche, seuls les patients moins anxieux avaient tendance à profiter de l'atténuation du comportement de la douleur, indiquant un degré moindre d'anxiété et de sensations somatiques durant la séance d'ergothérapie que les patients qui n'intervenaient pas. Les résultats semblent indiquer qu'il faudrait tenir compte de l'anxiété relative à l'état de santé durant les traitements.
$\mathrm{H}_{\mathrm{a}}$ ealth anxiety (HA) is the fear of or excessive worry about having a serious illness or disease, typically based on the misinterpretation of bodily signs and symptoms $(1,2)$. Such signs and symptoms most often include pain, gastrointestinal distress and cardiorespiratory complaints (3). The experience of HA varies from one person to another; thus, the HA construct has been conceptualized on a continuum ranging from mild to severe (eg, 4,5). Severe HA can be distinguished from nonclinical presentations by the degree of fear and conviction about having a serious illness, and the amount of distress and interference in functioning (eg, work performance, leisure activities, interpersonal relationships) $(6,7)$.

Recent research of HA in patients with chronic pain shows that it is related to increased pain, somatic sensations, avoidance and reassurance seeking, as well as greater attention to symptoms and dysfunctional pain-related cognitions (reviewed in 8). Furthermore, the relationship between HA and pain cannot be accounted for by other similar constructs such as pain-specific anxiety, anxiety sensitivity or trait anxiety (9).

The impact of HA on pain treatment has only recently been investigated empirically. Preliminary findings suggest that HA affects how patients respond to physiotherapy treatment. For instance, when compared with patients with low HA, those with higher HA have been found to worry more about their health and injury, and to attend to and catastrophically misinterpret sensations more frequently during physiotherapy (10). As well, HA appears to affect significantly how patients respond to the use of cognitive coping strategies during physiotherapy. Specifically, for patients with higher HA, attending to sensations results in lower anxiety and pain than engaging in distraction, whereas patients with lower HA show the reverse pattern (10). On this basis, it appears that the use of specific coping strategies, such as attention to sensations and distraction, differentially affects patients and, consequently, treatment processes, depending on the level of HA. Whether HA affects other aspects of the treatment process, such as treatment focused on pain behaviour, remains to be determined.

Patients communicate their pain through a wide variety of pain behaviours; verbal complaints, paralinguistic vocalizations, distorted ambulating or posture, gesturing, avoidance, display of limitations and facial expressions are common (11). These behaviours are known to reflect diverse factors such as tissue damage, adverse affects of dis- use or overguarding, individual differences, cultural background and contingent reinforcement from the environment (12). As such, they are considered important targets for chronic pain treatment. For example, operant conditioning aims to decrease pain behaviours and increase adaptive behaviours by altering social and environmental contingencies, and cognitive-behavioural therapy aims to modify the patient's subjective experience of pain and emphasizes the acquisition of cognitive and behavioural skills for coping with pain (13). In both types of treatment, patients are taught to recognize and reduce pain behaviour (14). Evidence suggests that both behavioural and cognitive-behavioural treatment programs are effective in decreasing physical and psychosocial disability $(15,16)$. Despite this evidence, there is little understanding of how patients specifically respond to instructions to reduce pain behaviour during therapy, and how this affects their symptoms, emotions and thoughts during treatment. In theory, if patients were able to reduce their pain behaviour, lower pain ratings, reduced somatic focus and fewer catastrophic thoughts should result. It is possible, however, that patients may have differential responses to these instructions depending on their level of HA.

The focus of the present investigation was to examine how patients with high and low levels of HA would respond to instructions to reduce pain behaviour during an occupational therapy session. Occupational therapy is often part of interdisciplinary pain treatment programs. It is characterized by job and home simulation exercises designed to assist patients in redeveloping the skills necessary for independent functioning, to enhance development and prevent disability, and to reduce avoidance and other forms of pain behaviour $(17,18)$. Occupational therapists often report that patients with chronic pain dislike this form of therapy and are more likely to demonstrate pain behaviour during occupational therapy than during other therapies, and thus maintain their focus on pain behaviour.

Based on previous research (10), it was predicted that, due to their increased focus on pain and worry about health, those with higher HA would not benefit from instructions to reduce pain behaviour and that these instructions would instead increase anxiety, somatic sensations and dysfunctional catastrophic thoughts. On the other hand, a reduction of pain behaviour among patients with lower HA was predicted to decrease somatic focus, anxiety and dysfunctional thoughts. 


\section{SUBJECTS AND METHODS}

\section{Participants}

Participants comprised patients attending an interdisciplinary pain treatment program over a 14 -month period. Patients were invited to participate if they had a routine, independent occupational therapy session; had approval from their occupational therapist to participate; and had experienced pain for at least three months. In total, 65 of 96 patients approached (68\%) agreed to participate. Their average age was $36.8 \pm 11.0$ years (mean $\pm \mathrm{SD}$ ), slightly more than half were male $(58.5 \%)$, the majority were married $(66.2 \%)$ and the average level of education attained was $12.0 \pm 2.3$ years. All participants were receiving financial compensation from the Workers' Compensation Board $(67.2 \%)$ or Saskatchewan Government Insurance (32.8\%). Participants' average pain duration was $15.6 \pm 23.6$ months (range three to 180 months). This duration of pain is considered chronic according to the International Association for the Study of Pain (19). Primary sites of pain reported by participants, coded according to the system of the International Association for the Study of Pain, were the back $(40 \%)$, followed by the upper shoulder and limbs $(21.5 \%)$, cervical region $(20.0 \%)$, lower limbs $(12.3 \%)$, pelvic region $(3.1 \%)$ and head $(3.1 \%)$.

\section{Measures \\ Demographic/background variables: Participants completed a background information questionnaire with questions about age, sex, marital status, education, compensation sta- tus, pain duration and primary pain site.}

Health anxiety: The Illness Attitudes Scale (IAS) (20) was used to assess HA. The IAS consists of 27 items examining fears, beliefs and attitudes related to HA rated on a 0 (no) to 4 (most of the time) scale. Three items were excluded from scoring because they have consistently been found to reflect the avoidance of poor health habits (eg, eating unhealthy foods, smoking) and not HA, and have been recommended for deletion from the scoring (21). The remaining items were averaged to form the HA score.

Pain experience: Pain during the session was measured using the short form of the McGill Pain Questionnaire (MPQ-SF) (22). The MPQ-SF is a valid and reliable measure, comprising an 11-item sensory pain subscale, a fouritem affect pain subscale, and a visual analogue scale and index for rating present pain intensity. The items of the sensory and affect subscales are rated on a scale from 0 (none) to 3 (severe). The MPQ-SF sensory subscale, derived by summing the intensity rank values of the sensory items, was of particular interest in the present investigation, and was used as a control variable before studying the main effects and interactions.

Somatic symptoms: Somatic symptoms were measured using the Somatic Symptom Subscale of the Symptom Checklist 90-R (23). This subscale assesses distress arising from perceptions of bodily dysfunction, including complaints focused on the cardiovascular, gastrointestinal, respiratory and other systems, with strong autonomic media- tion, as well as complaints of headache, pain and discomfort of the gross musculature (23). Completion of the Somatic Symptom Subscale involved rating the frequency of 12 symptoms during the therapy session on a scale of 0 (not at all present) to 5 (almost always present). The scale has been found to have high internal consistency (alpha 0.86) (23). Catastrophizing: Catastrophizing was assessed using the catastrophizing subscale of the Coping Strategies Questionnaire (24). Participants were asked to report the presence of various catastrophizing thoughts by rating the items on a scale of 0 (never) to 6 (always). The Coping Strategies Questionnaire has been found to be reliable and valid (25), and the study of catastrophizing has been found to be particularly useful in terms of understanding response to pain (26). State anxiety: The Beck Anxiety Inventory (BAI) (27) was administered to participants to assess state anxiety. The instructions were modified so that participants were asked to rate the extent to which they experienced various anxiety symptoms during the therapy session. The BAI consists of 21 items assessing anxiety severity on a scale of 1 (not experienced at all) to 4 (could barely stand it). The BAI has been shown to have high internal consistency (alpha 0.92) and high test-retest reliability over a period of one week $(\mathrm{r}[81]=0.75)(27)$.

Pain behaviour: An overall rating of pain behaviour was completed on a scale of 1 (no pain behaviour) to 7 (extreme pain behaviour) by an investigator observing the session. This type of global measure was chosen because of the heterogeneous nature of pain complaints in the sample (eg, back pain, shoulder pain). In previous research, a trained research assistant viewed videotaped therapy sessions and rated participants' overall pain behaviour. Inter-rater reliability for the coding by a second research assistant has been found to be satisfactorily high (alpha 0.80) (28). The investigator who rated patients in the present study served as the reliability coder on an earlier study (28). She was instructed to rate pain behaviour based on the presence of verbal complaints, paralinguistic vocalizations, distorted or ambulating posture, gesturing, touching or rubbing the affected area, avoidance, display of limitations and facial expressions. In the present study, participants also rated their own pain behaviour on two Likert scales (range 0 to 6 ), one reflecting verbal expression and other nonverbal pain behaviour, with higher scores indicating greater pain behaviour. Two scales of pain behaviour were included because, in pilot testing, it was apparent that it was easier for clients to rate their verbal and nonverbal behaviour separately on two scales than on one combined scale. For analysis, scores from these two scales were summed to obtain one measure of pain behaviour. Manipulation check: Participants rated the extent to which they understood the instructions ("Did you understand the instructions you were given prior to your session?") and followed the instructions ("Did you follow the instructions you were given prior to your session?") on two Likert scales (range 0 to 6). Higher scores represented a better understanding of the instructions, as well as greater adherence to the instructions. 


\section{Procedure}

Participants were invited to participate in the investigation by one of the authors. Those who provided informed consent to participate completed the IAS and a background information sheet. A second appointment was scheduled for participation, on average, within one week following their introduction to the investigation. At the second appointment, before beginning a routine, independent occupational therapy session, participants were randomly given one of two instructions. Both instructional sets began as follows:

I understand that you are experiencing pain and
discomfort during the occupational therapy session.
What I am interested in is the expression patients
use to communicate their pain or discomfort.
Some individuals say more and show that they
hurt more through body language, while others
don't say or do anything. Some people are verbally
expressive, they may say 'it hurts', 'ouch', or 'this
is uncomfortable'. Some people are non-verbally
expressive, they may grimace, limp, touch where it
hurts, or things like that. Individuals dealing with
pain often use expression, verbal and non-verbal,
to communicate their pain.

This introduction concluded with one of the following statements:

a) What I am interested in today is having you decrease your expression of pain. I would like you to be less expressive of your pain and discomfort during this session. For this session I would like you to not show it when you're feeling discomfort and pain. I would like you to try not to communicate when you feel pain. Try to be less verbally and non-verbally expressive. I'll be in the room watching this session. Try not to show expression when you are experiencing pain. Do you understand what I am asking you to do? Just try to be less verbally and non-verbally expressive than you usually are.

b) What I am interested in today is having you go through your session as you normally would. I'll be in the room observing. Use whatever expression you normally use to communicate discomfort or pain. Do you understand what I am asking you to do? Just go through the session as you normally do.

After receiving the instructions, all participants completed their routine occupational therapy session, which lasted an average of $25.4 \pm 10.7 \mathrm{~min}$. The therapy sessions varied from patient to patient because occupational therapy, by nature, is tailored to the client and includes job simulation exercises designed to assist the patient in redeveloping the skills necessary to carry out job functions. The investigator remained in the room to observe the session and rate the participants' pain behaviour. Immediately following the occupational therapy session, participants completed the questionnaires (excluding the IAS and demographic/background information sheet completed at the first appointment) and manipulation checks as described above.

\section{Manipulation check}

\section{RESULTS}

All participants reported having a good understanding of the instructions $(5.4 \pm 1.3)$ and indicated that they followed the instructions (5.6 \pm 0.9$)$. Results of ANOVA showed that there were no differences between the group instructed to inhibit pain behaviour and the control group in the extent to which they followed instructions $(F[1,63]=0.007$, $\mathrm{P}<0.93)$ or understood instructions $(\mathrm{F}[1,63]=0.69, \mathrm{P}<0.41)$. That participants followed the instructions was confirmed by ANOVA, which showed that those inhibiting pain behaviour were rated by the investigator as less expressive than control patients $(4.5 \pm 2.1$ versus $6.9 \pm 2.8$; $F[1,63]=16.01, P<0.0001)$. Similarly, in terms of participant ratings, those inhibiting pain rated themselves as less expressive than controls, $(2.3 \pm 2.8$ versus $4.6 \pm 2.2)$; $\mathrm{F}[1,63]=7.92, \mathrm{P}<0.01)$. There was also considerable agreement between the investigator and patients in ratings of expressiveness (alpha 0.70). No correlation was observed between HA and pain behaviour ratings made by patients and those made by the investigator, confirming that all patients responded to the instructions to the same degree.

\section{Hierarchical regression analyses}

To understand the extent to which HA is related to response to therapy and to determine whether instructions to reduce pain behaviour directly affect or moderate the effect of HA on response to therapy, a series of three-stage hierarchical multiple regression analyses were performed (see 29 for a discussion of moderator variables). In each analysis, the severity of pain, measured by the MPQ sensory subscale, was entered into step 1 to control for differences in pain experienced during the occupational therapy sessions. The instructional set variable (reduce pain behaviour versus control) and HA were entered into step 2 to test for the main effects of these variables on response to therapy, after controlling for pain severity. In step 3, the centred two-way interaction term between instructional set and HA (see 30 for a description of the centring process) was entered after controlling for the main effects from steps 1 and 2 (8). The dependent variables of interest were state anxiety, somatic sensations and catastrophizing. The results are reported in Table 1 and described in detail below.

\section{State anxiety}

In step 1 , the MPQ sensory pain subscale did not significantly affect anxiety during therapy. In step 2, HA and instructional set were entered after controlling for step 1, and a significant effect was seen. Further examination revealed that only HA predicted anxiety during the session; 
TABLE 1

Summary of hierarchical regression analyses examining predictors of anxiety, somatic sensations and catastrophizing during therapy

\begin{tabular}{|c|c|c|c|c|c|c|}
\hline Measure & Step & Variable & B & $\mathbf{t}$ & $F^{*}$ & $R^{2}$ change \\
\hline \multirow[t]{4}{*}{ Anxiety } & 1 & Pain severity & -0.11 & -0.87 & 0.76 & 0.01 \\
\hline & 2 & Instruction & 0.09 & 0.78 & $7.55^{\dagger}$ & $0.26^{\ddagger}$ \\
\hline & & Health anxiety & 0.50 & $4.56^{\dagger}$ & & \\
\hline & 3 & Interaction & -0.40 & $-1.80^{\ddagger}$ & $6.68^{\dagger}$ & $0.04^{\dagger}$ \\
\hline \multirow[t]{3}{*}{ Somatic sensations } & 1 & Pain severity & -0.03 & -0.26 & 0.07 & 0.00 \\
\hline & 2 & Instruction & 0.05 & 0.43 & $5.55^{\dagger}$ & $0.21^{\dagger}$ \\
\hline & & Health anxiety & 0.46 & $4.03^{\dagger}$ & & \\
\hline \multirow[t]{4}{*}{ Catastrophizing } & 1 & Pain severity & 0.31 & $2.61^{\dagger}$ & $6.81^{\dagger}$ & $0.10^{\dagger}$ \\
\hline & 2 & Instruction & -0.15 & -1.47 & $10.34^{\dagger}$ & $0.24^{\dagger}$ \\
\hline & & Health anxiety & 0.47 & $4.51^{\dagger}$ & & \\
\hline & 3 & Interaction & -0.30 & $1.41^{\ddagger}$ & $8.37^{\dagger}$ & $0.02^{\ddagger}$ \\
\hline
\end{tabular}

${ }^{*}$ Degrees of freedom are 1,63 for step 1, 2,61 for step 2 and 4,60 for step $3 ;{ }^{\dagger} P<0.01 ;{ }^{\ddagger}$ Marginally significant, $P<0.10$

those with higher HA reported greater anxiety during the session those with lower HA. In step 3, the centred twoway interaction terms were entered into the equation after controlling for the main effects entered in steps 1 and 2 . There was a clear trend for the interaction term to add a significant amount of variance to the prediction of anxiety during the session. Individuals with low HA who were instructed to inhibit pain behaviour reported lower anxiety than those who were instructed not to inhibit their pain behaviour (0.8 versus 1.2) (Figure 1). For those with high $\mathrm{HA}$, the reverse trend was observed; those who were instructed to inhibit their pain behaviour reported greater anxiety than those who were instructed not to inhibit their pain behaviour (1.80 versus 1.67$)$.

\section{Somatic sensations}

The same pattern was seen when somatic sensations experienced during therapy were examined. In step 1, pain severity did not significantly predict somatic sensations during the session. In step 2, HA and instructional set were entered after controlling for step 1, and a significant effect was seen. As noted above, further examination revealed that only HA predicted somatic symptoms during the session; those with higher HA reported greater somatic sensations during the session than those with lower HA. In step 3 , there was a clear trend for the interaction term to add a significant amount of variance to the prediction of anxiety. Individuals with low $\mathrm{HA}$ who were instructed to reduce their pain behaviour reported lower somatic sensations than those instructed not to do so (17.9 versus 22.6) (Figure 2). For patients with higher HA, the reverse trend was observed; those instructed to reduce their pain behaviour reported more somatic sensations than those instructed not to reduce their pain behaviour (33.3 versus 30.2 ).

\section{Catastrophizing}

In step 1, pain severity was found to predict catastrophizing; those who had higher pain severity ratings reported more

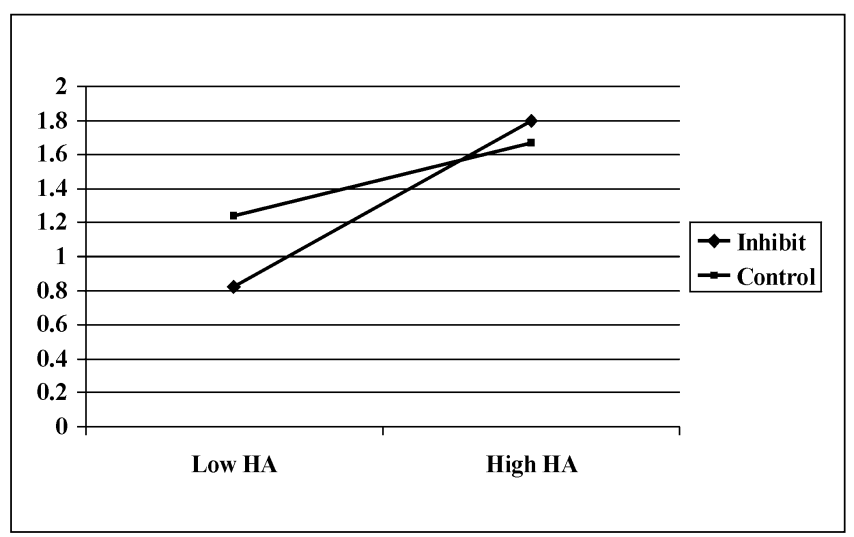

Figure 1) Anxiety as a function of health anxiety (HA) and instructions to inhibit pain behaviour

catastrophic thoughts. In step 2, when HA and instructional set were entered while controlling for the effect of pain severity, a significant effect was seen. As noted above, only HA significantly predicted catastrophizing; those with higher HA reported more catastrophic thoughts than those with lower HA. In step 3, there was also a trend for the interaction term to add a significant amount of variance to the prediction of response to the session. The interaction shows that, when individuals have low HA, instructional set has virtually no impact on catastrophizing ( 0.4 versus 0.4) (Figure 3); however, for those with high HA, instructions to inhibit pain behaviour result in an increase in catastrophic thoughts compared with instructions not to inhibit pain behaviour (2.3 versus 1.6 ).

\section{DISCUSSION}

Occupational therapy is an important context in which to study HA in persons with chronic pain. This therapy is routinely a component of interdisciplinary pain treatment programs and involves exercises designed to simulate tasks related to effective functioning at home or work. Clinical 


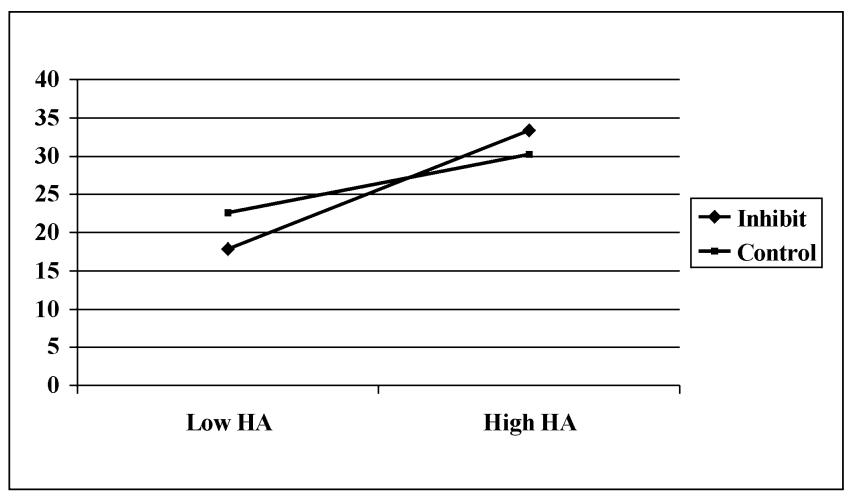

Figure 2) Somatic sensations as a function of health anxiety (HA) and instructions to inhibit pain behaviour

observations suggest that patients experience substantial anxiety and also demonstrate considerable pain behaviour within this context. In the present investigation, HA was found to have a significant impact on participants' responses to occupational therapy. Consistent with our hypotheses and previous research (eg, 10), HA was found to have a significant effect on pain response; when undergoing occupational therapy, individuals with higher HA experienced significantly greater state anxiety, somatic sensations and catastrophic thoughts than those with lower HA.

The results also showed some support for the hypothesis that instructing patients to reduce pain behaviour is beneficial in influencing how they respond to pain, but only among those with lower HA. That is, although all patients reduced their pain behaviour during the session, only patients with lower HA experienced a corresponding decrease in their experience of somatic sensations and anxiety. Among patients with higher HA, there was a consistent trend for reductions in pain behaviour to be associated with increased anxiety, somatic sensations and catastrophic thoughts. Although these findings did not reach the traditional level of significance (ie, $\mathrm{P}<0.10$, not $<0.05$ ), the consistent pattern across several dependent variables and the complexity of the designs relative to our overall sample size, suggest that the trend is likely of clinical importance.

In keeping with the conceptualization of HA as a continuous variable, we chose hierarchical regression analysis. In our preliminary data analysis, however, data were also analyzed using MANOVA. In this case, consistent with previous research in this area, patients were divided into low and high HA groups, with patients in the high HA group having IAS scores one standard deviation above the norm (8). HA (low and high) and instructional set (inhibit and control) served as the independent variables, and state anxiety catastrophizing and somatic sensations served as dependent variables. Results were similar to those found with the hierarchical regression. Using this less conservative approach (30), a significant multivariate interaction effect was seen. Furthermore, univariate follow-up analyses showed significant effects for somatic sensations, catastrophizing cognitions, and a trend for state anxiety.

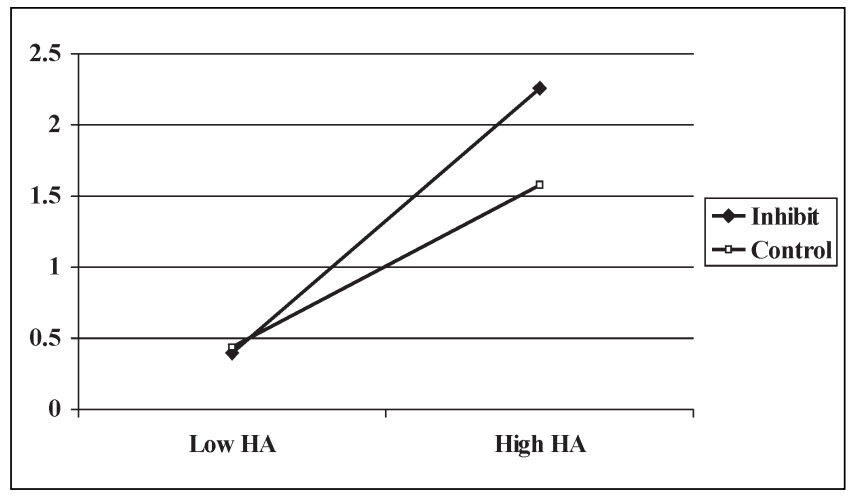

Figure 3) Catastrophizing as a function of health anxiety and instructions to inhibit pain behaviour

One potential mechanism underlying this interaction is that asking patients with higher HA to reduce their pain behaviour may inadvertently result in an increased attentional focus on their symptoms and, as a result, an increase in anxiety, somatic sensations and catastrophic thoughts. For those with lower HA, the opposite effect may occur. That is, when patients with low HA are asked to focus on reducing their pain behaviour, they may feel greater control over their symptoms and, thus, report less anxiety and somatic sensations.

In terms of clinical implications, the results confirm that $\mathrm{HA}$ is an important variable to address among patients receiving treatment for chronic pain, and that those with higher HA respond to therapy differently from those with lower HA. The findings from the present investigation, coupled with related observations (10), suggest that attempts to change the response patterns of patients with elevated HA may increase their anxiety in the short term. In the long term, however, patients with elevated HA may, with more effective training in reducing pain behaviour and distracting from pain, experience a reduction in anxiety similar to that shown by those with lower HA. The issues of whether the interaction trend seen in the present study is a function of sample size limitation, and whether long term therapeutic benefits from instructions to reduce pain behaviour might be achieved in patients with high HA remain to be determined. It is likely that both short term and long term benefits might be realized if these instructions were provided to patients with high $\mathrm{HA}$ along with related cognitive restructuring exercises.

Generally, the results of this investigation suggest that further research is needed in this area. First, as noted above, the results need to be replicated with larger samples. Second, examination of the impact of further education and experience with reducing pain behaviour in response to therapy would be a valuable direction for further research. Finally, examination of the variables that may explain the effects that were observed in this study may prove interesting. Does increased attentional focus on symptoms explain why patients with higher HA become more anxious and experience more somatic 
symptoms and catastrophic thoughts when they reduce their pain behaviour? Do increased feelings of control explain why those with lower HA benefit from reducing their pain behaviour during occupational therapy? Answers to these questions will ultimately serve to improve our understanding and treatment of HA in the context of chronic pain.

\section{REFERENCES}

1. Lucock MP, Morley S. The health anxiety questionnaire. Br J Health Psychol 1996;1:137-50.

2. Warwick HMC. A cognitive-behavioural approach to hypochondriasis and health anxiety. J Psychosom Res 1989;33:705-11.

3. Barsky AJ, Klerman GL. Overview: Hypochondriasis, bodily complaints, and somatic styles. Am J Psychiatry 1983;140:273-83.

4. Barsky AJ, Wyshak G, Klerman GL. Hypochondriasis: An evaluation of the DSM-III-R criteria in medical outpatients. Arch Gen Psychiatry 1986;43:493-500.

5. Salkovskis PM, Warwick HMC. Morbid preoccupations, health anxiety and reassurance: A cognitive-behavioural approach to hypochondriasis. Behav Res Ther 1986;24:597-602.

6. Barsky AJ, Fama JM, Bailey ED, Ahern DK. A prospective 4- to 5-year study of DSM-III-R hypochondriasis. Arch Gen Psychiatry 1998;55:737-44.

7. Robbins JM, Kirmayer LJ. Transient and persistent hypochondriacal worry in primary care. Psychol Med 1996;26:575-89.

8. Hadjistavropoulos HD, Owens KMB, Hadjistavropoulos T, Asmundson GJG. Hypochondriasis and health anxiety among pain patients. In: Asmundson GJG, Taylor S, Cox BJ, eds. Health Anxiety: Clinical and Research Perspectives on Hypochondriasis and Related Disorders. London: Wiley, 2001.

9. Hadjistavropoulos HD, Asmundson GJG. Health anxiety, pain-specific anxiety, anxiety sensitivity, and trait anxiety: Is there a difference in their ability to predict long-term disability? In: Sullivan MJL, ed. Determinants of Disability in Chronic Pain Patients: Research, Theory and Clinical Implications. Symposium presented at the Canadian Pain Society 2000 Annual Conference, Banff, May 11-13, 2000.

10. Hadjistavropoulos HD, Hadjistavropoulos T, Quine A. Health anxiety moderates the effects of distraction versus attention to pain. Behav Res Ther 2000;38:425-38.

11. Keefe FJ, Block AR. Development of an observation method for assessing pain behavior in chronic low back pain. Behav Res Ther 1982;13:363-75.

12. Fordyce WE, Roberts AH, Sternbach RA. The behavioural management of chronic pain: A response to critics. Pain 1985;22:113-25.

13. Turner JA, Clancy S. Comparison of operant behavioral and cognitive-behavioral group treatment for chronic low back pain. J Consult Clin Psychol 1988;56:261-6.

14. Keefe FJ, Bradley LA. Behavioral and psychological approaches to the assessment and treatment of chronic pain. Gen Hosp Psychiatry 1984;6:49-54.
ACKNOWLEDGEMENTS: This research was supported by a grant to Dr Hadjistavropoulos from the Saskatchewan Health Services Utilization and Research Commission. The assistance of staff and patients of the Functional Rehabilitation Program, Wascana Rehabilitation Centre, is gratefully acknowledged. We thank Linda Picot for her assistance in preparing the manuscript and Dr Don McCreary for his assistance with data analysis.

15. Keefe FJ, Dunsmore J, Burnett R. Behavioral and cognitivebehavioral approaches to chronic pain: Recent advances and future directions. J Consult Clin Psychol 1992;60:528-36.

16. Vlaeyen JWS, Haazen IWCJ, Schuerman JA, Kole-Snijders AMJ, van Eek H. Behavioral rehabilitation of chronic low back pain: Comparison of an operant treatment, an operant-cognitive treatment and an operant-respondent treatment. Br J Clin Psychol 1995;34:95-118.

17. American Occupational Therapy Association. Representative assembly minutes. Am J Occup Ther 1986;40:852.

18. Flower A, Naxon E, Jones RE, Mooney V. An occupational therapy program for chronic back pain. Am J Occup Ther 1981;35:243-8.

19. Classification of chronic pain. Descriptions of chronic pain syndromes and definitions of pain terms. Prepared by the International Association for the Study of Pain, Subcommittee on Taxonomy. Pain Suppl 1986;3:S1-226.

20. Kellner R, Abbott P, Winslow W, Pathak D. Fears, beliefs, and attitudes in DSM-III hypochondriasis. J Nerv Ment Dis 1987;175:20-5.

21. Hadjistavropoulos HD, Frombach I, Asmundson GJG. Exploratory and confirmatory factor analytic investigations of the Illness Attitudes Scale in a non-clinical sample. Behav Res Ther 1999;37:671-84

22. Melzack R. The short-form McGill Pain Questionnaire. Pain 1987;30:191-7.

23. Derogatis LR. SCL-90-R Administration, Scoring and Procedure Manual. Towson: Clinical Psychometric Research Inc, 1992.

24. Rosenstiel AK, Keefe FJ. The use of coping strategies in chronic low back pain patients: Relationship to patient characteristics and current adjustment. Pain 1983;17:33-44.

25. DeGood DE, Shutty MS. Assessment of pain beliefs, coping and self efficacy. In: Turk DC, Melzack R, eds. Handbook of Pain Assessment. New York: Guilford Press, 1992.

26. Lester N, Lefebvre JC, Keefe FJ. Pain in young adults. III. Relationships of three pain-coping measures to pain and activity interference. Clin J Pain 1996;12:291-300.

27. Beck AT, Epstein N, Brown G, Steer RA. An inventory for measuring clinical anxiety: Psychometric properties. J Consult Clin Psychol 1988;56:893-7.

28. Hadjistavropoulos HD, LaChapelle D. Extent and nature of anxiety experienced during physical examination of chronic low back pain. Behav Res Ther 2000;38:13-29.

29. Baron RM, Kenny DA. The moderate-mediator variable distinction in social psychological research: Conceptual, strategic, and methodological considerations. J Pers Soc Psychol 1986;51:1173-82.

30. Cohen J, Cohen P. Applied Multiple Regression/Correlation Analysis for the Behavioural Sciences, 2nd edn. Hillsdale: Earlbaum, 1983. 


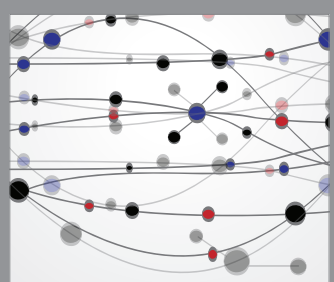

The Scientific World Journal
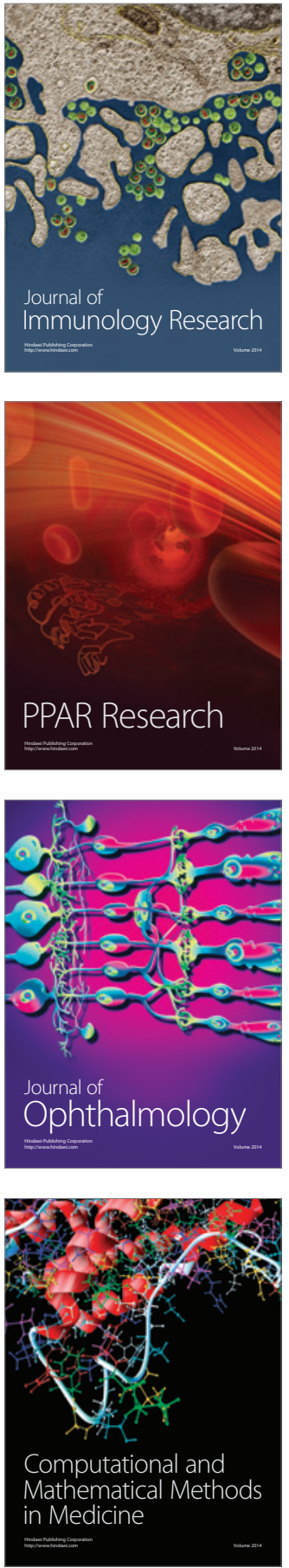

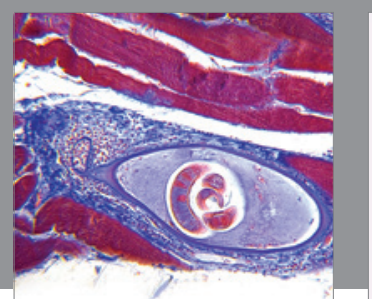

Gastroenterology Research and Practice

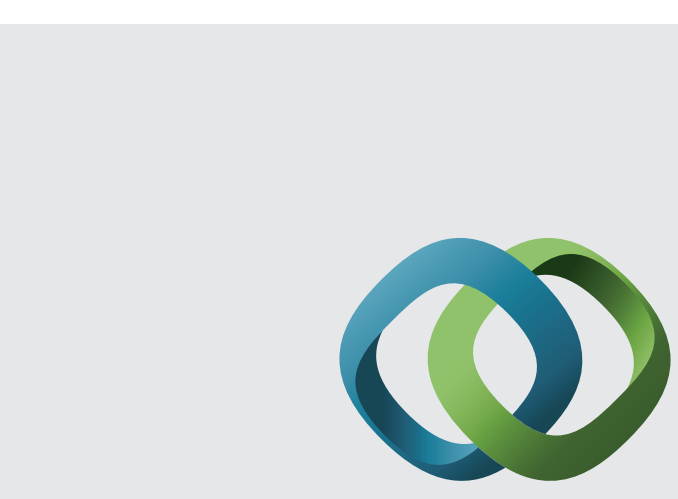

\section{Hindawi}

Submit your manuscripts at

http://www.hindawi.com
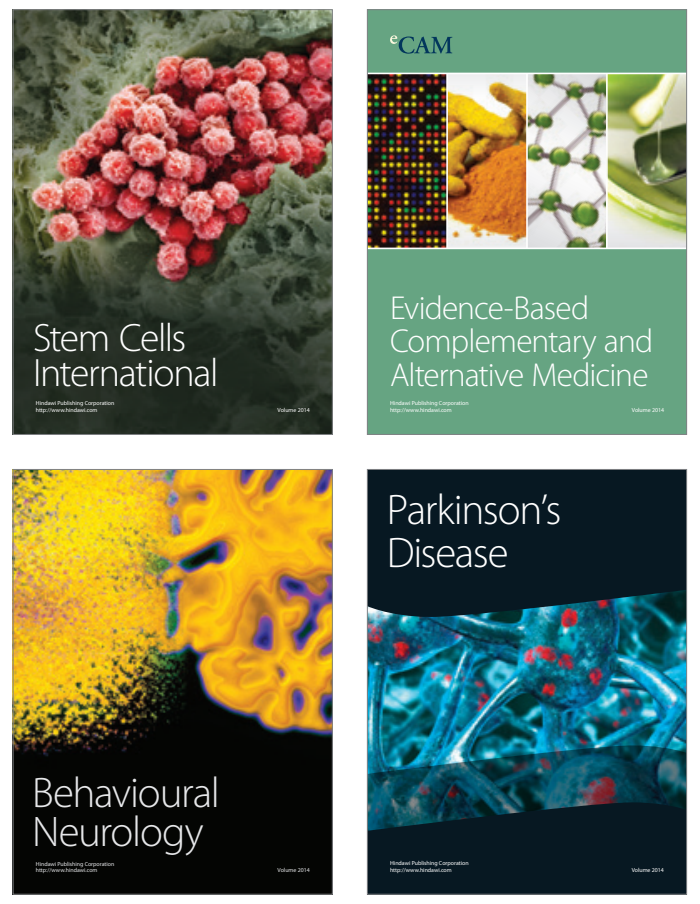
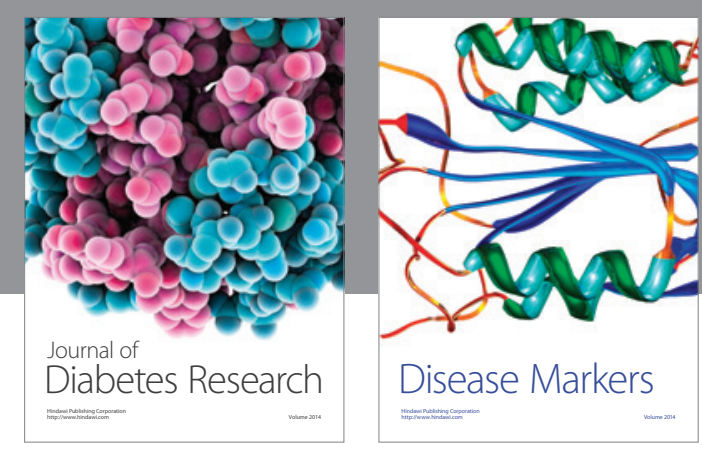

Disease Markers
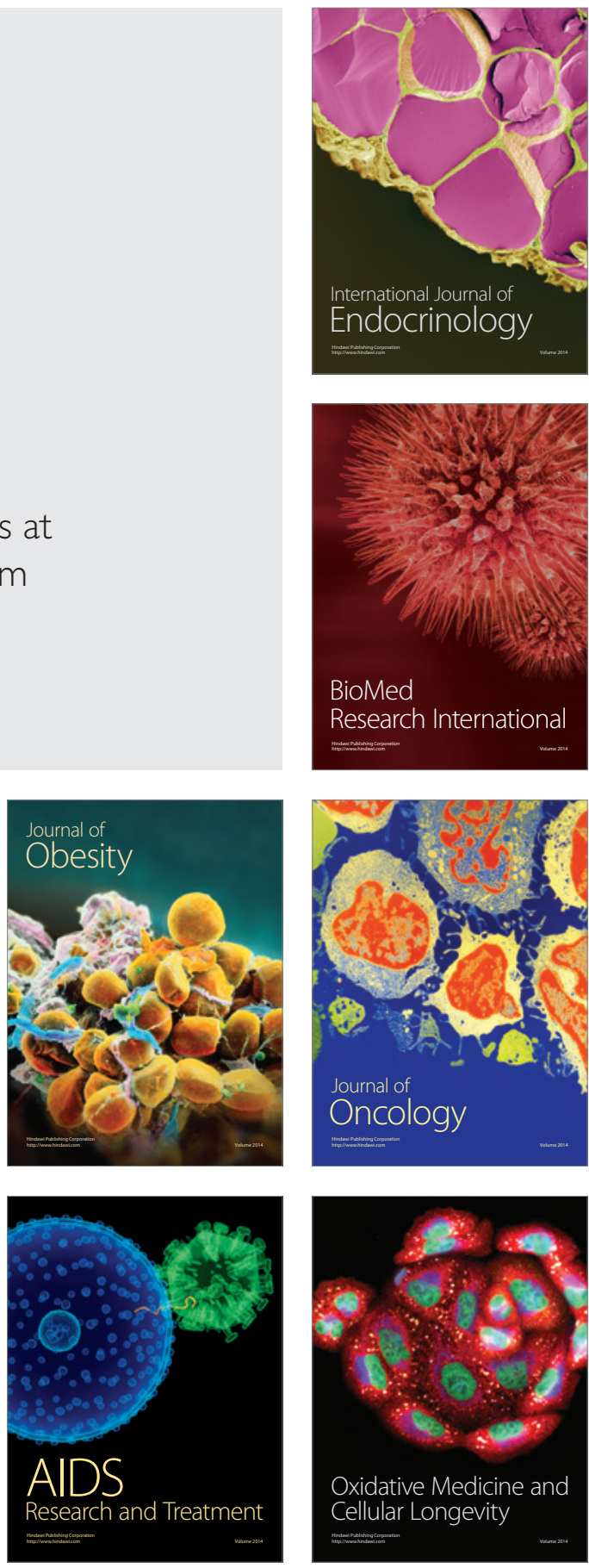